\title{
Acute Renal Failure as Part of Multi-Organ Failure: How Long We Should Wait before We Intervene? A Dissection of Studies
}

\author{
Najib Mohammad ${ }^{1}$ \\ Received: May 10, 2014 Accepted: September 23, 2014 doi: 10.3329/jemc.v5i1.21496
}

\begin{abstract}
Mortality rate in multisystem organ failure (MOF) is very high. Acute renal failure is an important part of MOF. In this special feature article I have aimed to streamline the achievements of different studies on continuous renal replacement therapy (CRRT) for a fruitful outcome. For this I have gone for retrospective evaluation of the studies reached through PubMed, internet alert system of different journals, proceedings of conferences on CRRT and personal communication with the experts in this field. I have evaluated the outcome of studies to explore the causes of failure to achieve a positive result and to identify the positive gains of studies. Finally, I have compiled the positive gains to outline a new strategy for future study and greater achievement. The findings of evaluation led to the conclusion that while planning for initiation of CRRT, multiple strategies should be targeted. The strategy should involve early initiation of CRRT guided by new markers of acute kidney injury (AKI), continuous venovenous hemofiltration (CVVH) modality, optimum intensity (intensity should be adequate enough to improve hemodynamics within a targeted period), selection of an effective filter membrane. Elderly patients should be studied in a different group. Cardiac patients with AKI should not be studied in the same group along with the patients with sepsis.
\end{abstract}

Key words: Acute kidney injury; Renal replacement therapy; Multisystem organ failure; Neutrophil gelatinase-associated lipocalin (NGAL); Continuous venovenous hemofiltration (CVVH); High volume hemofiltrationn ( $H V H F$ )

J Enam Med Col 2015; 5(1): 39-43

\section{Introduction}

Relentless efforts are going on to curtail the high mortality rates in multisystem organ failure (MOF) where sepsis and cardiac patients hold the major share. Kidney is not the first organ that is affected in the sequential organ failure process in MOF. In sepsisinduced acute kidney injury (AKI), usually it takes a week or more to knock down the kidneys. But in cardiac cases or post-cardiopulmonary bypass patients, acute renal failure (ARF) develops in hours. In cardiac cases, if the cardiac problems are solved early and timely, and renal replacement therapy is started early, the outcome is good. ${ }^{1,2}$ In most of the studies, cardiac cases are not separated from septic cases while evaluating for mortality outcome. ${ }^{3-5}$ Hence the statistical analysis for outcome is not a homogenous one. In sepsis-induced MOF, kidney is usually the third or fourth organ affected, after respiratory, hemodynamic involvement and/or disseminated intravascular coagulation (DIC). From the beginning of sepsis, the kidney resists the onslaught of mediators. While the mediators continue to assault the pulmonary, hemodynamic and other systems, the intensivists remain as "innocent watcher", waiting for the worsening of the kidney function before a decision is made for initiating renal replacement therapy (RRT). It is now a well-established practice to use continuous renal replacement therapy (CRRT) in ARF patients with hemodynamic instability ${ }^{6}$; but till now, no drug is

1. Associate Professor, Department of Intensive Care Medicine, Bangladesh Institute of Health Sciences General Hospital, Dhaka

Correspondence Najib Mohammad,Email:najib_mohmd@yahoo.com 
available to reverse the effects of mediators on the target organs. Now, the issue is - how long we should wait before we strike decisively with the therapeutic technologies available now? To what extent we should allow the kidneys to go down before we intervene?

It is only a modality of CRRT and a particular type of membrane that can eliminate the cytokines either by convection or by adsorption or both. ${ }^{7-9}$ There has been report of lowering of level of cytokines if convection is applied with higher intensity. ${ }^{10}$ Also, Simmons et al showed that those who died of ARF had much higher cytokine levels. ${ }^{11}$ So the use of convection is likely to be of better outcome. Herrera-Gutierrez et al showed that the patients who showed hemodynamic improvement had better outcome than those who did not improve hemodynamically. ${ }^{12}$

Most immunoassays detect only circulating mediators, not mediators bound to cells or receptors ${ }^{13,14}$, thus these may underestimate the effective amount of mediator acting at a cellular level. ${ }^{15}$ Still, once the cytokines are removed, there is reduction of onslaught by the mediators at cellular or receptor level. The author agrees with Lamiere et $\mathrm{al}^{15}$ that mere dialysis with CVVHD is of no curative value in sepsis-induced MOF. Mere correction of deranged renal profile will not help, the factors triggering MOF should be targeted also.

The issue of AKI in cardiac cases and sepsis cases has not been well-compared. Renal involvement in cardiac or cardiac surgery cases is immediate whereas in sepsis ARF comes about a week or so later. Early RRT in post-cardiopulmonary bypass (post-CPB) cases have shown promising outcome. ${ }^{1,2}$ Bouman et $\mathrm{al}^{3}$ did not show any survival difference with early High Volume Hemofiltration (HVHF) as compared to early Low Volume Hemofiltration and late Low Volume Hemofiltration. Their survival rates were high $(74.3 \%, 68.8 \%$ and $75.0 \%$ respectively). In this study more than $50 \%$ were cardiac surgery patients. The author feels that sepsis group outcome should not be amalgamated with cardiac group outcome because of different pathophysiological issues. In sepsis-induced ARF, pulmonary and/or cardiovascular system is affected early and then may or may not be followed by DIC while the kidneys continue to resist the mediator assault initially. Finally, the kidneys, a week or more later, give way - either show changes in urine output or elevation of creatinine.
Bouman et $\mathrm{al}^{16}$ has mentioned about "timely initiation of dialysis" as an important strategy. In sepsis-induced MOF, dialysis never helped except the study of daily hemodialysis (HD). ${ }^{17}$ Again the quality of the patients in this group was questioned. In the studies that showed improved mortality outcome, majority of those belonged to continuous venovenous hemofiltration (CVVH). 1,18,19 Hemofiltration not only corrects gross renal profile but also removes cytokines minimizing the assault on different vital organ systems although this modality does not affect the rate of production of cytokines which, it seems, vary from patient to patient. The rate of removal of cytokines depends on the strength of hemofiltration. ${ }^{10}$ One issue has not been well-addressed-the intensity of production of inflammatory mediators and the rate of its removal. As the rate of production of mediators is self-limiting, when it will stop or when the intensity of production will fall below a critical level is not known. But Pinsky et $\mathrm{al}^{20}$ have shown that those who died of MOF had much higher cytokine levels. Cornejo et $\mathrm{al}^{21}$ have shown that in refractory septic shock, reversal of shock needed much higher rate of hemofiltration. Conversely, Peng et $\mathrm{al}^{10}$ showed that hemofiltration at high rate $(70$ $\mathrm{mL} / \mathrm{kg} / \mathrm{hr}$ ) lowered the levels of multiple cytokines, but they did not show the mortality outcome.

In the RENAL Study ${ }^{4}$ and VA/NIH Acute Renal Failure Trial Network Study ${ }^{5}$ they used continuous venovenous hemodialysis filtration (CVVHDF) at a maximum strength of $35 \mathrm{~mL} / \mathrm{kg} / \mathrm{hr}$ and $40 \mathrm{~mL} / \mathrm{kg} / \mathrm{hr}$ respectively. But the maximum strength of hemofiltration in these two studies were very low $(17.5 \mathrm{~mL} / \mathrm{kg} / \mathrm{hr}$ and 20 $\mathrm{mL} / \mathrm{kg} / \mathrm{hr}$ respectively). Probably this is the reason why these two studies did not get any advantage over mortality outcome when compared with other studies with CVVH. Also in these two studies, cardiac cases were mixed with septic cases and the age of many patients seem pretty high (up to 80 years and 75 years respectively). Studies show that at older ages immune response is altered and mortality is high. ${ }^{22}$ So, the patients with old ages ( $\geqslant 70$ years) have to be grouped in another group to evaluate the survival.

The study of Saudan et $\mathrm{al}^{23}$ showed that mortality was higher in CVVH group than CVVHDF group. But CVVH group had more patients with cardiogenic shock or cardiac arrest. Also, Acute Physiology and Chronic Health Evaluation II (APACHE 11) score was higher in 
CVVH group ( $26 \pm 9$ vs $24 \pm 9$ ). It indicates that there were more critical patients in the CVVH group than CVVHDF group. Hence, the conclusion "adding dialysate to hemofiltration improves mortality" is questionable.

Till now only one study used AKI marker "Neutrophil Gelatinase-associated Lipocalin (NGAL)"24 to correlate with mortality outcome. This study showed that NGAL levels were higher in non-survivors compared to survivors. Hence, while decision for initiating RRT is made, issue of oliguria should be enforced by new renal biomarkers of $\mathrm{AKI}^{25,26}$, probably the rising level of NGAL is a strong choice.

\section{Indications for initiating RRT}

Only few studies have used oliguria as 'pointer' for initiating CRRT. 1,3,19 The concept of 'early initiation' of RRT had been using markers, viz., elevation of serum creatinine, urea, oliguria etc. ${ }^{27}$ But except in few cases, none had been rewarding. While it takes around 3 days to double the level of serum creatinine, it cannot be adopted as a marker for early initiation of CRRT. Oliguria may be a reasonable choice. Elahi et $\mathrm{al}^{1}$ have initiated CVVH 8 hours after oliguria and it showed improved mortality outcome in post-CPB patients. Other studies also showed similar outcome. ${ }^{2,19}$

Recently, there has been study on duration of oliguria and its relation to subsequent development of AKI using serum creatinine as a marker of ARF. ${ }^{28}$ Although oliguria for 4 hours showed a relationship to subsequent development of AKI, the duration of oliguria for 2 hours seems too early and also creatinine is not a good marker for early AKI. Probably, combination of a little longer oliguria and levels of new markers of AKI, viz., NGAL, hepcidin, kidney injury molecule-1(KIM-1), would provide a new approach for therapeutic intervention. $^{25,26,29}$ It seems now time is mature enough to replace creatinine with newer markers of AKI for therapeutic intervention in critically ill patients. Probably, it is a wise choice to target oliguria as an indication for initiating RRT. But the author feels it should be reinforced by the rising level of a marker of AKI, say NGAL, which is showing promising role as a marker of AKI in most recent studies. ${ }^{29}$ Also, while deciding on oliguric status, it has to be ensured that the intravascular compartment is well-filled.

\section{The intensity of CRRT}

Some studies have shown mortality outcome benefit using hemofiltration at a rate of $35-45 \mathrm{~mL} / \mathrm{kg} / \mathrm{hr}$. Some showed improved hemodynamics with much high volume of hemofiltration. ${ }^{18}$ Some studies showed that mortality outcome was improved in those who showed improved hemodynamics after iniating $\mathrm{CVVH} .{ }^{12,21}$

Peng et al showed lowering of cytokine levels at high level of CVVH. ${ }^{10}$ The principle should be that the 'intensity' should be adequate enough to flash out cytokines at a rate higher than the rate of production. There are literatures showing the changing levels of cytokines at sequential assessment. ${ }^{16,20}$ There are multiple cytokines with different molecular weights and it is difficult to monitor all of these. Then how to go clinically? Possibly it is by progressive increasing of the dose of hemofiltration from $35 \mathrm{~mL} / \mathrm{kg} / \mathrm{hr}$ to 45 $\mathrm{mL} / \mathrm{kg} / \mathrm{hr}$, and so on up to $70 \mathrm{~mL} / \mathrm{kg} / \mathrm{hr}$ in sequence, and simultaneously monitoring hemodynamics or 3-4 hours for each dose. ${ }^{10,18}$ If there is no hemodynamic improvement, the rate may be increased in incremental fashion after a targeted period, instead of mere watching for outcome indefinitely. If the hemodynamics improves, it may be presumed that an optimum rate of cytokine removal has been achieved thereby reversing the ultimate effect of nitric oxide on microvessels. Further if the positive fluid balance can be avoided by fluid removal without compromising hemodynamics, it may be presumed that capillary leak has stopped or brought under control. As the positive fluid balance has a relationship with mortality, the control over fluid balance is an additional advantage in the path of survival. ${ }^{30,31}$

The author suggests that while starting CRRT, 7 points have to be targeted.

1. Timing - early initiation of CRRT within 6-8 hours of oliguria with supportive supplement from 'rising' level of marker of AKI, viz., NGAL, within this period of oliguria. Serum creatinine is not a good marker for early detection of AKI. The initiation timing for RRT should be before irreversible damage is done.

2. Modality should be CVVH which uses convection to remove cytokines.

3. The membrane should be polyacrylonitrile which is capable of adsorption and convection. 
4. The intensity of hemofiltration, theoretically, has to be strong enough to remove cytokines at a rate higher than the rate of cytokine production. The improvement in hemodynamics may be considered as indirect evidence of intensity-goal. In order to achieve this goal, CVVH may be started at a hemofiltration rate of $35 \mathrm{~mL} / \mathrm{kg} / \mathrm{hr}$ and may be increased in sequence to $45 \mathrm{~mL} / \mathrm{kg} / \mathrm{hr}, 55 \mathrm{~mL} / \mathrm{kg} / \mathrm{hr}$ and so on up to $70 \mathrm{~mL} / \mathrm{kg} / \mathrm{hr}$ if there is no hemodynamic improvement within 3 to 4 hours of initiation of each dose.

5. Each patient has to be euvolemic for at least the same oliguric period - in other words, the intravascular compartment has to be well-filled before oliguria-related decision is made for initiation of CVVH.

6. Cardiac cases and sepsis cases have to be studied separately and then the outcomes may be compared.

7. For patients with old age ( $\geqslant 70$ years), the outcome has to be evaluated separately.

In summary, while dealing with ARF in MOF, approach to RRT should be multipronged. The plan should involve early initiation before irreversible damage is done, the modality should be CVVH with optimum hemofiltration intensity targeting hemodynamic improvement, membrane should be polyacrylonitrile (till better membrane is available) with adsorption and convection function. Patient has to be euvolemic for at least 6 hours during oliguria before oliguria is accepted for initiation of CVVH. Rising level of new markers of AKI should enforce the finding of oliguria before the decision is made for initiation of CVVH. To evaluate the outcome, the cardiac patients and sepsis patients have to be studied separately. Old age group $(\geqslant 70$ years) has to be studied separately because of age related multiple comorbidities. The therapeutic approach to ARF in MOF should be multiple, collective and intense rather than single or double pronged in order to have better outcomes.

\section{References}

1. Elahi MM, Lim MY, Joseph RN, Dhannapunani RR, Spy TJ. Early hemofiltration improves survival in post-cardiotomy patients with acute renal failure. Eur J Cardiothoracic Surg 2004; 26: 1027-1031.

2 Sugahara S, Suzuki H. Early start on continuous hemodialysis therapy improves survival rate in patients with acute renal failure following coronary bypass surgery. Hemodialysis Int 2004; 8(4): 320-325.

3. Bouman CS, Straaten HMO, Tijssen JG, Zandstra DF, Kesecioglu J. Effects of early high-volume continuous venovenous hemofiltration on survival and recovery of renal function in intensive care patients with acute renal failure: a prospective, randomized trial. Crit Care Med 2002; 30: 2205-2211.

4. The RENAL Replacement Therapy Study Investigators (Bellomo R, Cass A, Cole L, Finfer S, Gallagher M, Lo S et al). Intensity of continuous renal replacement therapy in critically ill patients. N Engl J Med 2009; 361(17): 1627-1638.

5. The VA/NIH Acute Renal Failure Trial Network (Palevsky PM, Zhang JH, O'Connor TZ, Chertow GM, Crowley ST, Choudhury D et al). Intensity of renal support in critically ill patients with acute kidney injury. N Engl J Med 2008; 359: 7-20.

6. Prowle JR, Sneider A, Bellomo R. Clinical review: optimal dose of continuous renal replacement therapy in acute kidney injury. Critical Care 2011; 15: 207.

7. De Vriese AS, Colardyn FA, Philippe JJ, Vanholder RC, De Sutter JH, Lameire NH. Cytokine removal during continuous hemofiltration in septic patients. J Am Soc Nephrol 1999; 10: 846-853.

8. Heering P, Morgera S, Schmitz FJ, Schmitz G, Willers R, Schultheiss HP et al. Cytokine removal and cardiovascular hemodynamics in septic patients with continuous venovenous hemofiltration. Intensive Care Med 1997; 23(3): 288-296.

9. Bellomo R, Tipping P, Boyce N. Continuous venovenous hemofiltration with dialysis removes cytokines from the circulation of septic patients. Crit Care Med 1993; 21(4): 522-526.

10. Peng Z, Pai P, Hong-Bao L, Rong L, Han-Min W, Chen H. The impacts of continuous veno-venous hemofiltration on plasma cytokines and monocyte human leukocyte antigenDR expression in septic patients. Cytokine 2010; 50: 186-191.

11. Simmons EM, Himmelfarb J, Sezer MT, Chertow GM, Mehta RL, Paganini EP et al. The PICARD Study Group. Plasma cytokine levels predict mortality in patients with acute renal failure. Kidney International 2004; 65: 1357-1365.

12. Herrera-Gutierrez ME, Seller-Perez G, Lebron-Gallardo M, Munoz-Bono J, Banderas-Bravo E, Cordon-Lopez A. Early hemodynamic improvement is a prognostic marker in patients treated with continuous CVVHDF for acute renal failure. ASAIO J 2006; 52(6): 670-676.

13. Beutler B. Endotoxin, tumor necrosis factor, and related mediators: new approaches to shock. New Horizons 1993; 1: $3-12$. 
14. Bone RC. Immunologic dissonance: a continuing evolution in our understanding of the systemic inflamatory response syndrome (SIRS) and multiple organ dysfunction syndrome (MODS). Ann Intern Med 1996; 125: 680-687.

15. Lameire N, Vanbiesen W, Vanholder R. When to start dialysis in patients with acute kidney injury? When semantics and logic become entangled with expectations and beliefs. Crit Care 2011; 15: 171.

16. Bouman CSC, Straaten HMO, Schultz MJ, Vroom MB. Hemofiltration in sepsis and systemic inflammatory response syndrome: the role of dosing and timing. Journal of Critical Care 2007; 22: 1-12.

17. Schiffl H, Lang SM, Fischer R. Daily hemodialysis and the outcome of acute renal failure. N Engl J Med 2002; 346: $305-310$.

18. Ronco C, Bellomo R, Homel P, Brendolan A, Dan M, Piccini $P$ et al. Effects of different doses of continuous veno-venous hemofitration on outcomes of acute renal failure: a prospective randomized trial. Lancet 2000; 356: 26-30.

19. Piccini P, Dan M, Barbacini S, Carraro R, Lieta E, Marafon $\mathrm{S}$ et al. Early isovolaemic haemofiltration in oliguric patients with septic shock. Intensive Care Med 2006; 32: $80-86$.

20. Pinsky MR, Vincent JL, Deviere J, Alegre M, Kahn RJ, Dupont E. Serum cytokine levels in human septic shock. Relation to multiple-system organ failure and mortality. Chest 1993; 103(2): 565-575.

21. Cornejo R, Downy P, Castro R, Romero C, Regueira T, Vega $\mathrm{J}$ et al. High-volume hemofiltration as salvage therapy in severe hyperdynamic septic shock. Intensive Care Medicine 2006; 32: 713-722.

22. Tran DD, Groenereld AB, van der Meulen J, Nauta JJ, van Schijndel RJS, Thijs LG. Age, chronic disease, sepsis, organ system failure and mortality in a medical ICU. Crit Care Med 1990; 18(5): 474-479.
23. Saudan P, Niederberger M, De Seigneux S, Romand J, Pugin $\mathrm{J}$, Perneger $\mathrm{T}$ et al. Adding a dialysis dose to continuous hemofiltration increases survival in patients with acute renal failure. Kidney International 2006; 70: 1312-1317.

24. Kumpers P, Hafer C, Lukasz A, Lichtinghagen R, Brand K, Fliser D et al. Serum neutrophil gelatinase-associated lipocalin at inception of renal replacement therapy predicts survival in critically ill patients with acute kidney injury. Critical Care 2011; 14: R9.

25. Moore E, Bellomo R. Novel biomarkers of acute kidney injury: ready for clinical application? Current Opinion in Critical Care 2010; 16: 523-525.

26. Haase-Fielitz A, Mertens PR, Plass M, Hermann K, Hetzer $\mathrm{R}$, Westerman $\mathrm{M}$ et al. Urine hepcidin has additive value in ruling out cardiopulmonary bypass-associated acute kidney injury - an observational cohort study. Critical Care 2011; 15: R186.

27. Palevsky PM. Indications and timing of renal replacement therapy in acute kidney injury. Crit Care Med 2008; 36(Suppl): S224-S228.

28. Prowle JR, Yan-Lun L, Licari E, Bagshaw SM, Egi M, Haase $\mathrm{M}$ et al. Oliguria as predictive biomarker of acute kidney injury in critically ill patients. Crit Care 2011; 15: R172.

29. Singer E, Elger A, Elitok S, Kettritz R, Nichokas TL, Barasch $\mathrm{J}$ et al. Urinary neutrophil gelatinase-associated lipocalin distinguishes pre-renal from intrinsic renal failure and predicts outcomes. Kidney Int 2011; 80: 405-414.

30. Vincent JL, Sakr Y, Sprung CL, Ranieri VM, Reinhart K, Gerlach $\mathrm{H}$ et al. Sepsis in European intensive care units: results of SOAP study. Crit Care Med 2006; 34: 344-353.

31. Boyd JH, Forbes J, Nakada T, Walley KR, Russell JA. Fluid resuscitation in septic shock: a positive fluid balance and elevated central venous pressure are associated with increased mortality. Crit Care Med 2011; 39: 259-265. 